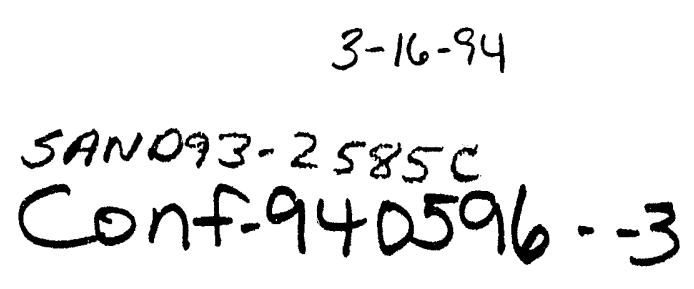

\title{
The Iniluence of Temperature and Fumidity on the Wettability of Immersion Tin Coated Printed Wiring Boards
}

\author{
U. Ray and I. Artaki \\ AT\&T Bell Laboratories, Princeton, NJ 08542 \\ and \\ P.T. Vianco \\ Sandia National Laboratories, Albuquerque, NM 87185
}

\begin{abstract}
This paper investigates the merits and drawbacks of immersion tin coatings as potential printed wiring board (PWB) surface finishes. Immersion tin films app.ied in various thicknesses $(0.2$ to 2 $\mu \mathrm{m})$ to different copper substrates were characterized relative to thermal stability and shelflife. Thermal excursions included those typical in mixed technology assembly processes. Exposure to temperature/humidity was varied from near ambient $\left(35^{\circ} \mathrm{C} / 85 \% \mathrm{RH}\right)$ to harsh (steam aging). A minimum thickness of $-60 \mu$ in $(1.5 \mu \mathrm{m})$ was determined to be critical for assembly operations involving multiple thermal excursions. Even though formation of $\mathrm{Cu}-\mathrm{Sn}$ intermetallic compounds (IMC) is facile, at the copper-tin interface, these compounds do not adversely affect the soldering performance, as long as the IMC phase is protected by a tin surface layer. Immersion tin finishes are relatively stable to thermal exposure, but are readily oxidized in the presence of humidity. This oxide growth is directly responsible for solderability degradation.
\end{abstract}

The underlying copper substrate was also found to have a significant impact on the thermal stability of tin films. An electroless copper substrate caused significantly more intermetallic formation, that resulted in poor solderability even under moderate temperature, humidity conditions.

\section{INTRODUCTION}

Replacement of the conventional SnPb surface finish on printed wiring boards (PWB) is driven by a number of factors, including the anticipated regulatory or legislative mandates against lead use in electronic products, as well as by the requirement for flat, planar surfaces for fine and ultra-fine pitch surface mount assembly. Options for solderability preservative coatings on printed wiring boards include organic films (azole or rosin/resin based) and plated metallic coatings.

The advantages of organic azole coatings are well recognized; organic films are lead-free and meet the planarity requirement. However they lack the thermal stability to withstand multiple elevated temperature thermal exposures in non-inert environments. ${ }^{[1]}$ Thin metallic films (e.g. tin, gold) may provide enhanced thermal stability; moreover, they may be more compatible with many of the emerging lead-free interconnection solders.

Immersion tin is a potential surface finish, which in the past found limited applications due to its apparently poor shelf life and vulnerability to humidity exposure. The cause of these phenomena is not well understood, nor well documented.

* This work was supported in part by the U.S. Dept. of Energy under contract DEAC04-94AL85000

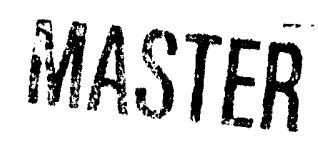

as MniBUTION OF THIS DOCUMENT is UNLIMITE 
Based on the need for an alternative finish to acconnodate lead-free solder assembly, immersion tin coatings are being re-examined to assess their viability and range of applicability to electronic processing.

This paper investigates the merits and drawbacks of electroless tin coatings as potencial PWB surface finishes. Immersion tin films applied in various thicknesses $(0.2$ to $2 \mu \mathrm{m})$ to different copper substrates were characterized relative to thermal stability and shelflife. Thermal excursions included those typical in mixed technology assembly processes. Exposure to temperature/humidity was varied from near ambient $\left(35^{\circ} \mathrm{C} / 85 \% \mathrm{RH}\right)$ to harsh (steam aging).

The solder wettability of immersion tin was monitored both by wetting balance measurements and area-of-spread (Sessile drop) methods. Intermetallic compound (IMC) growth kinetics was measured by Rutherford Back Scattering Spectroscopy and Glancing Angle X-Ray Diffraction as a function of tin coating thickness and nature of the PWB copper substrate (electroless and electroplated copper conductors). The growth of surface tin oxide was probed by Auger Electron Spectroscopy and X-Ray Photoelectron Spectroscopy.

To assess the practical benefits and limitations of immersion tin finishes, fine pitch surface mount components were attached to tin finished PWB pads using $\mathrm{SnPb}$ as well as eutectic $\mathrm{SnAg}$ and $\mathrm{SnBi}$ solders. The results of these surface mount assembly evaluations are presented.

\section{EXPERIMENTAL METHODS}

\section{Sample Preparation}

Copper laminates were degreased and microetched in a sodium persulphate/sulphuric acid solution. The electroless (immersion) tin coating is a commercial formulation (Shipley LT34) and was applied according to the supplier's recommended procedure. The thickness of the immersion tin coatings (as measured by X-Ray Fluorescence) ranged from 15 to $70 \mu$ inches, depending on the immersion time and bath temperature. For example, 1 hour immersion at $50^{\circ} \mathrm{C}$ resulted in a tin coating approximately $60 \mu$ inch $(1.5 \mu \mathrm{m})$ thick.

\section{Film Characterization}

Optical microscopy on cross-sectioned specimens is the most commonly used technique for the study of intermetallic compounds. Attempts to cross-section the tin films in this study were unsuccessful owing to the thinness of these coatings. Hence, spectroscopic techniques such as RBS and X-ray diffraction were performed to study IMC growth in these thin (1-2 um) tin films. The physical metallurgy of the tin films was studied using surface analytical techniques that included X-Ray Photoelectron Spectroscopy (XPS) and Auger Electron Spectroscopy (AES). A Surface Science Laboratories Model SSX-206 Spectrometer using a $600 \mu$ monochromatized AI $\mathrm{K} \alpha \mathrm{X}$-ray photon beam (1486.6eV) was used for XPS analysis. A Physical Electronics PHI Model 610 Scanning Auger Microprobe was used for the Auger studies and employed a $3 \mathrm{KV}, 1 \mu \mathrm{A}$ electron beam rastered over a $100 \mathrm{~h}^{2}$ area. A SKV, $10 \mathrm{nA}$ (total current) beam rastered over a $1 \mathrm{~mm}^{2}$ area was used for depth profiling analysis (oxide thickness determination studies) and yielded a sputter rate of $-10 \AA / m i n u t e$. All XPS and AES experinients were performed under ultra-highvacuum (1.5 $\times 10^{-9}$ torr). Intermetallic compound growth kinetics were measured by Rutherford backscattering spectroscopy (RBS). These experiments were performed in an accelerator where monoenergetic $4 \mathrm{He}^{+}$ions (1mm dia spot size) were bombarded into the sample target and a small fraction of the back scattered ions were collected into an energy sensitive detector. The energy of the backscattered particles provided a signature of the target atoms. The $\mathbf{X}$ Ray diffraction measurements were performed with a Siemens D500 diffractometer, with Cu radiation. Standard theta/2theta runs were done using focusing slits, a curved graphite diffracted beam monochromator and a scintillation detector. The identification of the various intermetallic phases was performed by glancing-incidence $\mathbf{X}$ Ray diffraction (GIXRD). Glancing incidence runs were done using a non focusing optical arrangement consisting of (from the detector side) $0.1^{\circ}$ scatter silts, $0.2^{\circ}$ set of long slits, a flat crystal LiF diffracted beam monochromator and a scintillation detector. The glancing incidence angle was determined by first calculating the critical angle for total reflection of $\mathrm{CuSn}$ and determining a depth of penetration which will produce $66 \%$ of the diffraction information garnered from the substrate. The incidence angle was adjusted to produce information from only the top 1/3 of the film and also from the entire film. The sample was held at the critical angle from the $X$-ray source and the detector was scanned around 2theta. Typical scans were taken at $0.05^{\circ}$ steps for 10 seconds at each step. The morphology of the copper substrate and of the deposited tin was studied by Scanning Electron Microscopy (SEM).

\section{Aging Treatments}

The stability of the tin films was studied as a function of temperature and humidity exposure, as described below. 
i. Shelf Life: Storage at room temperature $\left(20^{\circ} \mathrm{C}\right.$ ) for a period of up to six weeks.

ii. Thermal Aging: Exposure to $100^{\circ} \mathrm{C}, 125^{\circ} \mathrm{C}$ and $175^{\circ} \mathrm{C}$ for 1 hour in a circulating air oven. These temperatures were selected to represent the range of conditions typical in electronics assembly processes. For example, multilayer PWBs are routinely subjected to a bake at $125^{\circ} \mathrm{C}$ for 1 hour to remove moisture. To simulate the conditions in a typical surface mount assembly process, the specimens were also exposed to the solder reflow furnace cycle for one and two passes in air.

iii. Temperature/Humidity Aging : Exposure to standard temperature/humidity $(\mathrm{T} / \mathrm{H})$ conditions (Bellcore, IPC) of $35^{\circ} \mathrm{C} / 85 \% \mathrm{RH}$ and $65^{\circ} \mathrm{C} / 85 \% \mathrm{RH}$ for periods ranging from 1 hour to 1 week. In addition, to isolate effects due to temperature and humidity, a set of samples was also exposed to $65^{\circ} \mathrm{C}$ under ambient humidity conditions (<50\%RH).

\section{Wettability Test}

The wettability of the coated substrates was assessed with a commercial wetting balance, ${ }^{[2]}$ the Multicore Universal Solderability Tester (MUST) and also by the Sessile drop (area-of-spread) method. In the wetting balance measurements, a $63 \mathrm{Sn}-37 \mathrm{~Pb}$ (weight \%) alloy was used with a commercial low-solids flux. Wetting force and wetting time were the parameters used from the wetting balance tests to provide a semiquantitative means for comparing the surface finishes and their associated processing conditions. Eutectic $\mathrm{SnPb}(0.125 "$ diameter) preforms were placed on thermally conditioned immersion tin specimens and reflowed in the infrared furnace. The area-of-spread of the reflowed solder preform was calculated by averaging over the longest and shortest diameters.

\section{RESULTS AND DISCUSSION}

\section{Thermal Effects}

The thermal stability of immersion tin surface finishes was investigated as a function of the applied coating thickness and the morphology of the underlying copper substrate. Copper conductors/lands on PWBs were electroplated or electrolessly deposited. The topography of the underlying copper substrate appeared to influence the morphology and porosity of the immersion tin film, which in turn can affect its thermal stability and solderability. The following two sections address these issues in detail.

\section{Tin on electroplated copper}

Since electroplated copper conductors are more commonly used in the fabrication of PWBs, the major part of our investigation was focussed on immersion tin finishes on electroplated copper substrates. The thermal stability of immersion tin appliea in three different thicknesses was studied. Figure 1 summarizes the results of an area-ofspread study performed on $15 \mu$ inch, $30 \mu$ inch and $60 \mu$ inchl tin films subjected to various degrees of thermal stress. The conditions on the $\mathrm{X}$-axis are a qualitative ranking of increased thermal severity. Generally, the area-of-spread increases with increasing tin coating thickness. Prior to heating, the area-of-spread of the solder preform on the 60uinch film, (which is comparable to the area obtained on typical Hot Air Solder Levelled or azole coated substrates), is approximately a factor of three higher than that associated with the $15 \mu$ inch film, indicating that the thinner film is likely to exhibit reduced solderability in an assembly environment. A $15 \mu$ in coating thickness does not provide adequate wettability even prior to any thermal exposure and will probably not be acceptable in manufacturing. A minimum tin thickness of $\sim 60 \mu$ in appears to be necessary for assembly where the PWBs are exposed to multiple thermal cycles. The films appear to show a slight decrease in spreading with the severity of thermal treatment. The tin coating with a nominal

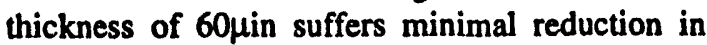
solderability upon multiple exposures to the reflow furnace cycle.

The heat induced degradation of solderability can be caused by two factors: oxidation of the tin surface or growth of the Cu-Sn intermetallic phase. To examine the surface oxidation of the tin films, XPS analyses were performed. Figure 2 shows the XPS spectra of 60 $\mu$ in thick tin-coatings as a function of thermal treatment in the Sn 3d high resclution region. Fig 2 (a) is from a freshly deposited sample and (b) and (c) are from samples which have undergone one and two reflow cycles in air respectively. It should be noted that the samples have undergone a "simulated" reflow operation, where no solder paste was actually printed. The samples only passed through the reflow oven operated under standard condition for $\mathrm{Sn}-\mathrm{Pb}$ reflow to experience the thermal effects.

In Fig 2, the peaks at 486.6 and $495.0 \mathrm{eV}$ are the $3 d_{1 / 2}$ and $3 d_{3 / 2}$ levels of metallic $S n$. The peaks at 484.8 and 493.1 are the corresponding peaks for $\mathrm{SnO}_{\mathrm{x}}$. It is clear from Fig 2 that the freshly deposited sample shows a thin $(-40 \AA$, estimated from the intensity of the $\mathrm{Sn}^{0}$ peak and the escape depth of electrons from a tin surface) layer of 
$\mathrm{SnO}_{x}$ over the $\mathrm{Sn}$ metal. The intensity of the metallic Sn peak decreases at the expense of the $\mathrm{SnO}_{\mathrm{x}}$ peak after the samples were subjected to reflow. However, even after two reflows in air, the entire surface is not oxidized, as is evident from the non-zero Sn peak in Fig 2(c). This indicates that the oxide layer is not much more than $50-60 \AA$ s after two passes through the reflow oven. Similar oxidation behavior is also evident for the thinner coatings (data not shown). The thickness of the oxide layer after thermal treatment is independent of the tin coating thickness (over the 15-60 $\mu$ in range investigated here).

The affinity of $\mathrm{Cu}$ and $\mathrm{Sn}$ to form intermetallics is well documented in literature. ${ }^{[3]}[4]$ [5] ${ }^{16]}$ The mobility of $\mathrm{Cu}$ atoms in $\mathrm{Sn}$ at room temperature is sufficiently high such that the growth of $\mathrm{Cu}-\mathrm{Sn}$ intermetallic phases occurs in the film even at room temperature. At elevated temperatures, the intermetallic growth rate is significantly higher. Since the growth of the intermetallic phase and its subsequent oxidation, is known to degrade the solderability of tin, RBS studies were performed to follow the $\mathrm{Cu}-\mathrm{Sn}$ reaction as a function of temperature and coating thickness. RBS is a well established technique for depth profiling and quantitative material analysis. ${ }^{[7]}[8]$

Figure 3 shows the RBS spectra of backscattered $3 \mathrm{MeV} 4 \mathrm{He}^{+}$ions as a function of tin thickness and thermal treatment. The abscissa of the graph is the energy of the backscattered $\mathrm{He}$ ions ( 1 channel= $6 \mathrm{KeV}$ ). The scans labeled (a), (b) and (c) are, respectively, from $15 \mu \mathrm{in}, 30 \mu \mathrm{in}$ and $60 \mu \mathrm{in}$ thick tin coatings. In addition, each figure is a composite of curves from the "as deposited" (no heat) sample and from samples after exposure to $175^{\circ} \mathrm{C}$ for 30 minutes. The arrows labelled $\mathrm{Sn}$ (channel \#437) and $\mathrm{Cu}$ (channel \#381) indicate the backscattered energy position of $\mathrm{Sn}$ and $\mathrm{Cu}$ if they were to appear on the surface of the sample. Because tin is deposited on copper, the $\mathrm{Cu}$ backscattered energy position has been displaced to lower energy due to the top Sn layer. This energy shift can be used as an accurate measurement of the tin thickness.

An examination of Figure 3 reveals that before heating, the tin and copper form relatively well defined separate layers, with very little intermetallic mixing. Significant changes in the spectra occur after thermal exposure, especially for the thinner coatings. In all cases, the intensity of the Sn signal was lower and broadened to lower energy, so as to overlap that of $\mathrm{Cu}$, indicating the formation of the intermetallic phase. As seen in Fig 3 (a) and (b), the intermetallic phase has completely consumed the tin layer, and has reached the surface. This is shown in the spectrum, where the $\mathrm{Cu}-\mathrm{Sn}$ phase has reached channel \#381, which is the backscattered position for $\mathrm{Cu}$. For the 60uin coating shown in Fig 3(c), even though a significant amount of tin has been converted into an intermetallic after heating, there is still unreacted tin on the surface. In fact, from the relative intensities, we can calculate the intermetallic phase to be approximately two-thirds of the original $\mathrm{Sn}$ coating deposited. That is, approximately $40 \mu$ in of the Sn layer (originally 60 $\mu$ in) has been converted into a Cu-Sn intermetallic phase after this thermal treatment.

The identity of the exact intermetallic phases and their distribution as one goes through the tin layer can be understood from Glancing Incidence XRay Diffraction (GIXRD) studies. Figure 4 shows the GIXRD spectrum of a $60 \mu$ in tin coating heated for 30 minutes at $175^{\circ} \mathrm{C}$. The major peaks are identified on the figure. The primary component is $\mathrm{Cu}_{6} \mathrm{Sn}_{5}$, with a minor amount of $\mathrm{Cu}_{3} \mathrm{Sn}$. It is clear that close to the tin surface (see scan labelled $200 \AA$, which indicates $200 \AA$ from the surface), there is no detectable intermetallic compound (IMC) present. The IMC phase begins to grow at depths more that $900 \AA$ and is the major component of the spectrum beyond $3000 \AA$. The GIXRD study corroborates the earlier RBS results (Fig 3(c)) that for a 60 $\mu$ in coating, thermal treatment results in considerable IMIC formation, but the IMC is protected by a virgin surface tin layer. This tin layer is also not heavily oxidized.

The presence of the $\mathrm{Cu}-\mathrm{Sn}$ intermetallic phase affects the solderability behavior of the tin coating. The tin coatings exhibit progressively reduced solderability with decreasing coating thickness, as evidenced by the area-of-spread measurements shown in Figure 1. The solderability of these coatings is further deteriorated upon heating. The RBS studies demonstrated that for the thinner coatings, the intermetallic phase is a significant component of the tin layer even in the absence of heating and it entirely consumes the tin layer upon heating. The $60 \mu$ in coating, however, preserved one third of its original thickness even after excessive heating. The formation of $\mathrm{Cu}-\mathrm{S} n$ intermetallic compounds is not necessarily detrimental for solderability so long as these compounds do not reach the surface and oxidize. A protective tin layer is required to insure surface wettability. The minimum thickness of this protective layer has not been well defined. ${ }^{[6]}{ }^{[9]}$ Based on these results, it can be concluded that the typical thermal processes associated with mixed technology assembly will not cause the intermetallic phase to reach the surface, provided the tin coating thickness is maintained across the PWB surface above $\sim 60$ $\mu$ in. These studies have demonstrated the 
importance of maintaining an adequate tin thickness in order to achieve good yields during multi-step soldering processes. Ideally, a thicker tin layer should provide better corrosion protection. However, since the film is applied by an immersion process, it reaches self-limiting thickness. The two variables (solution temperature $=50^{\circ} \mathrm{C}$ and immersion time $=1$ hour) were optimized in this study for consistent coating uniformity. Heating the tin solution to temperatures above $50^{\circ} \mathrm{C}$ causes decomposition of the tin salts. Immersion times much longer than an hour are deemed impractical for manufacturing.

\section{Role of Copper substrate}

The role of the substrate topography was investigated through a series of spectrosopic studies. Three different copper substrates were included in this study:

1. Oxygen free high conductivity (OFHC) copper (sheet stock), 1/8" thick.

2. Electroplated copper on FR-4 (1 oz or 0.0014 in)

3. Electrolessly deposited $\mathrm{Cu}$ on FR-4 ( 1 oz or 0.0014 in)

The three different substrates were coated with immersion tin to a nominal thickness of 60 $\mathrm{in}$. OFHC copper was used as a baseline to determine the role (if any) that the epoxy-glass laminate might have on the coating performance. Figure 5 depicts the solderability data obtained with the wetting balance, before and after thermal treatment. The parameter selected for comparison is the wetting force at 2 seconds, expressed in $\mathrm{mN} / \mathrm{mm}$. The solderability of the tin film coated over both OFHC copper and electroplated copper is relatively unaffected by heat. However, the tin film deposited on the electroless copper substrate suffers a dramatic loss of solderability after exposure to $175^{\circ} \mathrm{C}$ for 30 minutes. XPS studies performed on all three tin coated substrates indicate that the tin oxide thickness was approximately equal on all. Therefore, the solderability degradation of tin on electroless copper is not caused by excessive tin oxide formation.

To probe the Cu-Sn intermetallic phase, RBS studies were performed on the tin over electroless copper specimens. The RBS spectra are shown in Figure 6. Spectrum 6(a) is taken from "as deposited" tin prior to any thermal treatment. A comparison of Fig 6(a) and Fig 3(c) (corresponding to the equivalent tin film deposited on an electroplated copper substrate) demonstrates that even at room temperature, the reaction of tin with electroless $\mathrm{Cu}$ is much more facile than that with electroplated $\mathrm{Cu}$. Significant $\mathrm{MMC}$ is formed after heating at $125^{\circ} \mathrm{C}$ for 1 hour (Fig $6(b)$ ). Heating at $175^{\circ} \mathrm{C}$ for 30 minutes causes a complete conversion of the tin layer into the intermetallic phase (Fig 6(c)). Note that the tin deposited on electroless $\mathrm{Cu}$ appears to be at least 30-50\% thicker (channel 200-450) than on electroplated $\mathrm{Cu}$ (channel 260-450), even though both substrates were exposed together to the same immersion tin chemistry for equal lengths of time.

A set of normal XRD studies confirm the above results. Figure 7 shows the XRD spectra of "as deposited" tin on electroless (Figure 7(a)) and electroplated (Figure 7(b)) Cu. From the labelled peaks, it is clear that $\mathrm{Cu}_{6} \mathrm{Sn}_{5}$ is a major peak on the electroless $\mathrm{Cu}$ specimen, while on electroplated $\mathrm{Cu}$, only peaks arising from $\mathrm{Sn}$ and $\mathrm{Cu}$ are present on the surface. Both the tin coating and the $\mathrm{Cu}_{6} \mathrm{Sn}_{5}$ IMC show preferred texture on the [101] plane. The amount of $\mathrm{Cu}_{6} \mathrm{Sn}_{5}$ increases with baking; $\mathrm{Cu}_{3} \mathrm{Sn}$ also appears in the layer.

Therefore, it appears that the rate of intermetallic compound growth is considerably faster on electroless copper compared to electroplated copper substrates, even at room temperature. The thicker intermetallic phase has a deleterious effect on solderability, as discussed in the previous section. Thus, it can be concluded that electroless copper may not be compatible with immersion tin finishes, especially in applications that require some form of thermal treatment. These results will be combined with those in the following section to develop a hypothesis to explain this behavior.

\section{Temperature/Humidity/Aging Effects}

\section{Tin on Electroplated copper}

In the preceding sections, we have shown that a 60 $\mu$ in tin coating on an electroplated copper substrate has excellent thermal stability. Previously ${ }^{[10]}$, we have shown that a combination of temperature and humidity has an adverse effect on the wettability of tin coated surfaces. Those studies have shown that immersion tin coatings do not survive the standard 8 hour steam aging requirement and undergo fairly rapid solderability degradation under moderate temperature and high relative humidity $(\mathrm{RH})$ conditions.

In order to isolate the effects due to temperature and humidity, specimens were exposed to one of the two following humidity conditions (high and low) at the same temperature for 1-6 days; (i) $65^{\circ} \mathrm{C} / 85 \%$ RH or (ii) $65^{\circ} \mathrm{C} / 35 \% \mathrm{RH}$. The wetting force data are presented in Figure 8. Exposure to $65^{\circ} \mathrm{C} / 85 \%$ RH for 1 day results in poor solderability, whereas the surface is still 
solderable after 6 days exposure to $65^{\circ} \mathrm{C} / 35 \%$ RH. Also shown in Figure 8 are results from an exposure to moderate temperature/high humidity conditions of $35^{\circ} \mathrm{C} / 905 \mathrm{RH}$. This exposure has a less severe impact, but is still responsible for a notable degradation in solderability after 6 days. Therefore, it is evident that the dominant factor which affects the wettability behavior of tin is humidity $\left(65^{\circ} \mathrm{C} / 85 \% \mathrm{RH}\right.$ vs $65^{\circ} \mathrm{C} / 35 \% \mathrm{RH}$ data) and this effect is accentuated at elevated temperatures $\left(35^{\circ} \mathrm{C} / 90 \% \mathrm{RH}\right.$ vs $\left.65^{\circ} \mathrm{C} / 85 \% \mathrm{RH}\right)$. For 1 and 3 day exposure, neither temperature or humidity alone affect wetting. Rather, it is a synergistic effect. After exposure to 6 days, the effect of humidity is more noticeable. However, the largest influence is still the combination of temperature and humidity.

The presence of a high humidity in elevated temperature environments can either cause faster IMC growth at the $\mathrm{Cu} / \mathrm{Sn}$ interface and/or facilitate chemical changes at the Sn surface. Both mechanisms can cause the surface to become unsolderable. In order to analyze changes in the chemistry of the tin surface upon temperature/humidity exposure, XPS studies were performed on the aged samples. Figure 9 shows the high resolution XPS spectra in the Sn 3d region. Spectrum (a) is from an "as deposited" sample, spectrum (b) is from a sample exposed to $65^{\circ} \mathrm{C} / 35 \% \mathrm{RH}$ for 8 hours, and spectrum (c) is from a sample exposed to $65^{\circ} \mathrm{C} / 85 \% \mathrm{RH}$ for 8 hours as well. The relative intensity of the $\mathrm{Sn}$ and the $\mathrm{SnO}_{\mathbf{x}}$ peak is approximately equal in spectra (a) and (b), showing that exposure to $65^{\circ} \mathrm{C} / 35 \% \mathrm{RH}$ does not increase the amount of surface oxide. However, the introduction of 85\%RH results in complete conversion of the surface metallic tin to tin oxide, as demonstrated by the absence of the metallic Sn peak from the spectrum. Since XPS can only measure surface concentration, AES depth profile studies were conducted on the same samples to determine the thickness of the tin oxide. The results are summarized in Figure 10. It is clear from Fig 10, that in the presence of $85 \% \mathrm{RH}$ at $65^{\circ} \mathrm{C}$, about $150 \AA$ of oxide are formed in 8 hours; this oxide continues to grow almost linearly with prolonged exposure to high humidity. However, the rate of oxide growth is not significant upon exposure to elevated temperatures, in the absence of high humidity conditions. RBS studies have shown that the rate of IMC formation is not affected by the presence of humidity.

A comparison of Figs 8 and 10 shows that the solderability of immersion tin coatings is directly related to the $\mathrm{SnO}_{x}$ growth on the surface; the thicker the oxide layer, the less solderable the surface. The combination of temperature and humidity significantly accelerates oxide growth. It is clear that the mechanism of oxide growth is catalyzed by the presence of water or hydroxyl ions. It is possible that in the presence of water or moisture, a hydrated tin oxide or a tin hydroxide is formed on the surface. This is consistent with earlier studies on oxidation of tin, ${ }^{[11]}$ where exposure to $80^{\circ} \mathrm{C}$ in $90 \% \mathrm{RH}$ was shown to produce $30 \%$ thicker tin oxide than comparable exposure at $100^{\circ} \mathrm{C}$ in low humidity.

\section{Role of Copper Substrate}

The AES/XPS/Wetting balance data for tin coatings on electroplated and electroless copper, as a function of temperature and humidity are summarized in Table 1 . The table contains surface concentration, oxide thickness and intermetallic thickness. These samples were exposed to $65^{\circ} \mathrm{C} / 85 \%$ RH for 8 hours and 24 hours and the solderability was measured by the wetting balance technique.

Table 1: Comparison of tin coatings on electroless and electroplated copper

$\mathrm{EP}=$ Electroplated copper; $\mathrm{EL}=$ Electroless copper

\begin{tabular}{|c|c||c|c|c|}
\hline Sample & $\begin{array}{c}65^{\circ} \mathrm{C} / 85 \% \text { RH } \\
\text { Exposure } \\
\text { (hours) }\end{array}$ & $\begin{array}{c}\text { Oxide } \\
\text { thickness } \\
(\AA)\end{array}$ & $\begin{array}{c}\text { IMC } \\
\text { formation }\end{array}$ & $\begin{array}{c}\text { Wetting } \\
\text { Force } \\
(\mathrm{mN} / \mathrm{mm})\end{array}$ \\
\hline \hline EP0 & 0.0 & 80.0 & negligible & 0.18 \\
\hline EP8 & 8.0 & 100.0 & negligible & 0.12 \\
\hline EP24 & 24.0 & 120.0 & negilgible & -0.01 \\
\hline \hline EL0 & 0.0 & 80.0 & negligible & 0.22 \\
\hline EL8 & 8.0 & 110.0 & extreme & 0.09 \\
\hline EL24 & 24.0 & 120.0 & extreme & -0.22 \\
\hline
\end{tabular}

As seen in Table 1, for electroplated samples, the wettability starts degrading after 24 hours exposure. However, for electroless samples, there is a marked decrease in the wetting force even after an 8 hour exposure. The 24 hour exposure causes the sample to be totally unsolderable. Therefore, these results are consistent with our earlier thermal exposure studies. That is, immersion tin coatings on electroless copper have a different response to temperature and humidity also than when deposited on electroplated copper.

The AES experimental procedure was altered in order to study both the surface oxide thickness and also $\mathrm{Cu}-\mathrm{Sn}$ intermetallic growth. The data clearly showed that although the surface oxide thickness increased with exposure to temperature and humidity, the increase was not significantly different to explain the poor solderability of the tin on electroless copper sample which was exposed to $65^{\circ} \mathrm{C} / 85 \% \mathrm{RH}$ for 24 hours as compared to the 
electroplated copper substrate. Comparison of the AES depth profiling results for the electroplated and electroless copper substrates reveals that the electroless copper substrate is more susceptible to intermetallic formation. This observation confirms the earlier RBS data (section 3.1.2). The AES studies demonstrated that there was extensive IMC formation close to the surface of the immersion tin on electroless copper after 8 hour exposure to $65^{\circ} \mathrm{C} / 85 \% \mathrm{RH}$, which directly correlates with the lack of solde rability. Therefore, the relatively poor solderability of immersion tin on electroless copper is caused by the more extensive growth of intermetallic.

Figure 11 shows the SEM micrographs of (a) electroless copper, (b) electroplated copper, (c) tin on electroless copper and (d) tin on electroplated copper at $10,000 \mathrm{X}$. The difference in surface topography between the two copper substrates is evident. The tin coated on electroless copper appears to follow the substrate topography. However, it is shown in Fig. 11 (d) that the tin coating on electroplated copper has an entirely different surface morpohology than the copper it was deposited on. XRD analyses show that the crystallographic orientation of $\mathrm{Sn}$ is identical on both the electroless and the electroplated substrates; the tin is preferentially aligned to the [101] plane in both cases.

The difference in the extent of intermetallic formation observed between the electroplated and the electroless copper substrates may be caused by variations in the physical metallurgy of the two coatings. The finer grain structure, which appears to characterize the electroless coatings, may quicken the reaction kinetics of IMC formation by short-circuiting the diffusion processes responsible for IMC growth. For example, a greater propensity for grain boundary diffusion (that would enhance IMC growth) is expected from the finer microstructure of the electroless coatings. Evidence to the effect of the physical metallurgy of the solder/substrate couple on interfacial reaction kinetics was observed by Vianco et. al.$^{[12]}$ In that study, a comparison was made of the solid state growth of copper/tin IMC layers formed with hot-dipped $100 \mathrm{Sn}$ coatings and those formed with electroplated 100Sn coatings. The substrate material was kept unchanged in this study (copper); the metallurgy of the tin-coating was varied. In general, the growth rate was faster with the electroplated coatings than with the hotdipped tin coating. It was concluded that the finer grain structure of the electroplated finish accelerated the growth of the IMC layers as compared with the case of the hot dipped coatings. A similar result was obtained in that work for the $63 \mathrm{Sn}-37 \mathrm{~Pb}$ coatings.
It does not appear likely that the observed data trends were caused by the effect of surface morphology on the AES or RBS experimental techniques. It was noted that the electroless deposit had a finer structure relative to the electroplated copper coating. A finer surface morphology would necessarily imply a larger effective surface area. However, the increased effective surface area would apply to each of the copper, tin and IMC components of the system so that the signal ratios would remain unchanged. This hypothesis assumes that the AES and RBS beam sampling areas were larger than the characteristic dimensions of surface asperities. Therefore, differences in the degree of IMC formation between the electroless and electroplated copper substrates would not be explicitly dependent on the surface morphology of the copper layers.

\section{SURFACE MOUNT ASSEMBLY EVALUATION}

To assess the practical benefits and limitations of immersion tin finishes on typical surface mount circuit board assembly processes, fine pitch surface mount components were attached to immersion tin finished PWB pads using 63Sn$37 \mathrm{~Pb}$ (weight\%) as well as two lead-free solder pastes (eutectic $96.5 \mathrm{Sn}-3.5 \mathrm{Ag}$ and $42 \mathrm{Sn}-58 \mathrm{Bi}$ ). The performance of the tin finish was also compared with that of an azole-based organic solderability finish (imidazole). Details of this study are documented elsewhere. ${ }^{[1]}$ Solder paste reflow was performed under both air and inert $\mathrm{N}_{2}$ atmosphere using a convection IR furnace. Reflow profiles were generated for each solder paste according to their melting point range and reflow behavior. Component leads and terminations were plated with $100 \%$ tin.

Most of the lead-free alloys are known to be less wettable than the $\mathrm{SnPb}$ alloys. ${ }^{[13]}$ The most recurring defect for the lead-free and the $\mathrm{SnPb}$ solders was incomplete wetting of the circuit board pads. Incomplete wetting was largely observed at the sharp corners of the land pattern, on boards assembled in both nitrogen and air.

Figure 12 compares the incidence of non-wetted pads on imidazole and immersion tin finished circuit boards after assembly with the eutectic $\mathrm{Sn}: \mathrm{Ag}, \mathrm{Sn}: \mathrm{Bi}$ and $\mathrm{Sn}: \mathrm{Pb}$ solders. The results shown in Figure 12 indicate that the immersion tin coating improves solder wetting when compared to the imidazole coated boards. Therefore the benefits of immersion tin are most apparent for assembly applications requiring solders with reduced spreading properties.

\section{CONCLUSIONS}


A comprehensive study was performed to examine the thermal stability and shelflife of immersion tin surface finish as a function of coating thickness and copper substrate morphology.

A minimum thickness of $-60 \mu$ in $(1.5 \mu \mathrm{m})$ was determined to be critical for assembly operations involving mutiple thermal excursions. Exposure to heat was shown to promote Cu-Sn intermetallic compound growth between the copper and tin layers. For thinner coatings $\leq 30 \mu \mathrm{in}$, moderate thermal cycles resulted in complete conversion of the tin layer to intermetallic compound, resulting in severe degradation of solderability. Formation of the Cu-Sn intermetallic phases, however, does not adversely affect the soldering performance of the thicker coatings, as long as the intermetallic phase is protected by a tin surface layer. For a coating thickness of $60 \mu$ in or above, thermal excursions associated with typical assembly operations result in a conversion of $40-60 \%$ of the tin layer into $\mathrm{Cu}-\mathrm{Sn}$ compounds. Since that leaves considerable amount of unreacted tin, these finishes perform well in operations requiring multiple heating steps. This is in contrast with thin organic azole films, which are known to lack thermal stability. ${ }^{[10]}$

The immersion tin finishes, however, are readily oxidized in the presence of humidity. Prolonged exposure to high humidity, even at ambient temperatures, result in a marked degradation in solderability. A series of controlled experiments, where temperature and humidity were independently varied, demonstrated that the growth of tin oxide is catalyzed by the presence of water vapor. This oxide growth was directly responsible for poor soldering performance. RBS and XRD experiments have demonstrated that IMC growth was not a factor in the soldering performance under moderate temperature, high humidity conditions.

An oxide layer of $\sim 150 \AA$ is formed after exposure to $65^{\circ} \mathrm{C} / 85 \% \mathrm{RH}$ for only 8 hours. Under ambient temperature and humidity conditions, shelf-life was found to be better than 6 weeks. However, an increase in relative humidity to $90 \%$ under moderate temperatures, makes these tin surfaces unsolderable after two weeks. Therefore, it is clear that storage of tin finished PWBs in a controlled temperature and humidity environment is critical for subsequent good soldering yields.

The underlying copper substrate was also found to have a significant impact on the thermal stability of tin films. An electroless copper substrate caused significantly more intermetallic formation even at room temperature, that resulted in poor soldering performance. With the current immersion tin chemistry available, the use of immersion tin surface finishes with electroless copper PWBs is not recommended.

Evaluations of lead-free solder pastes for surface mount assembly applications indicated that immersion tin coated PWBs resulted in better spreading of Sn:Ag and $\mathrm{Sn}: \mathrm{Bi}$ solder alloys as compared to the azole based finishes. Therefore, for future assemblies with lead-free solders, an understanding of current tin chemistries is critical. The limitations of the current process require further work in making the tin coating less moisture sensitive.

\section{ACKNOWLEDGEMENT}

We acknowledge the help and support of H. M. Gordon for sample preparation and solderability analyses, A. M. Jackson for surface mount assembly studies, G. S. Heyer, A. Lieberich, P. J. Sakach and R. E. Woods for peforming the surface analyses and $M$. O. Eatough of Sandia National Labs for assistance with the XRD studies. The help of F. Unterwald with the RBS experiments is also acknowledged.

\section{REFERENCES}

1. I. Artaki, U. Ray, H.M. Gordon, R.L. Opila, "Corrosion protection of copper using organic solderability preservatives", in

Proceedings of Surface Mount International Conference, 1992, pg 503

2. D. MacKay, Proc. Internepcon, Brighton, England; Cahners Exposition Group, Chicago, II., 1970.

3. K.N. Tu, R.D. Thompson, "Kinetics of interfacial reaction in bimetallic Cu-Sn thin films", Acta Metallurgica, Vol. 30, 1982, pg 947.

4. Tu K.N., "Interdiffusion and reaction in bimetallic $\mathrm{Cu}-\mathrm{Sn}$ thin films", Acta Metallurgica, vol. 21, 1973, pg 347.

5. P. J. Kay and C. A. Mackay, "The growth of intermetallic compounds on common basis materials coated with tin and tin-lead alloys", Trans of the Inst of Metal Finishing, Vol 54, 1976, pg 68.

6. P. E. Davis, M. E. Warwick and S. J. Muckett, "Intermetallic compound growth and solderability of reflowed tin and tin-lead coatings", Plating and Surface Finishing, vol. 70, 1983, pg 49.

7. W. -K. Chu, J. W. Mayer and M. -A. Nicolet, Backscattering Spectrometry, ... London: Academic Press Inc., 1978. 
8. L. C. Feldman and J. W. Mayer. Fundamentals of Surface and Thin Film Analysis, New York: North-Holland, 1986.

9. P. E. Davis, M. E. Warwick and P. J. Kay, "Intermetallic Compound Growth and Solderability", Plating and Surface Finishing. Vol. 69 1982, pg 72.

10. I. Artaki, U. Ray, P. Vianco, A. M. Jackson and H.M. Gordon, "Solderabiltity Preservative Coatings: Electroless Tin vs Organic Azoles", in Proceedings of the Surface Mount International Conference, 1993, pg 414.

11. H. Fidos and K. Piekarski, Jrl. of Inst. of Metals, vol 101, 1973, pg 95.

12. P. Vianco, P. Hlava and A. Kilgo, in "Intermetallic Compound Layer Formation between Copper and Hot-Dipped 100In, 50In$50 \mathrm{Sn}, 100 \mathrm{Sn}$ and $63 \mathrm{Sn}-37 \mathrm{~Pb}$ Coatings", J. Electronic Mater., to be published, 1994.

13. Vianco P.T., Hosking F.M., Frear D.R., "Lead-free solders for electronic applications wetting analysis", Proceedings of the 4th Electronic Materials and Processing Congress - ASM International, 1991, pg 373.

\section{DISCLAIMER}

This report was prepared as an account of work sponsored by an agency of the United States Government. Neither the United States Government nor any agency thereof, nor any of their employees, makes any warranty, express or implied, or assumes any legal liability or responsibility for the accuracy, completeness, or usefulness of any information, apparatus, product, or process disclosed, or represents that its use would not infringe privately owned rights. Reference herein to any specific commercial product, process, or service by trade name, trademark, manufacturer, or otherwise does not necessarily constitute or imply its endorsement, recommendation, or favoring by the United States Government or any agency thereof. The views and opinions of authors expressed herein do not necessarily state or reflect those of the United States Government or any agency thereof. 


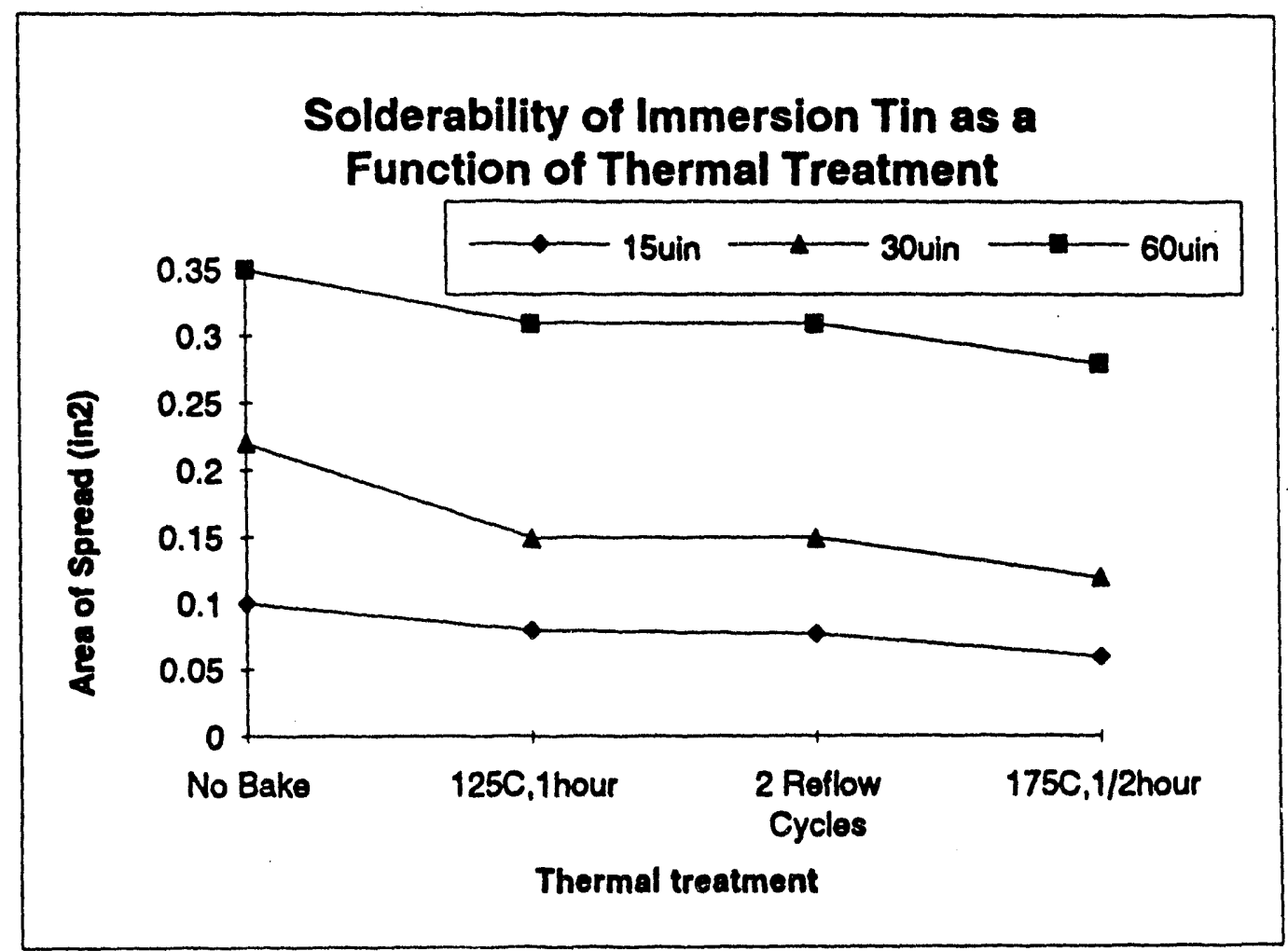

FIGURE 1 

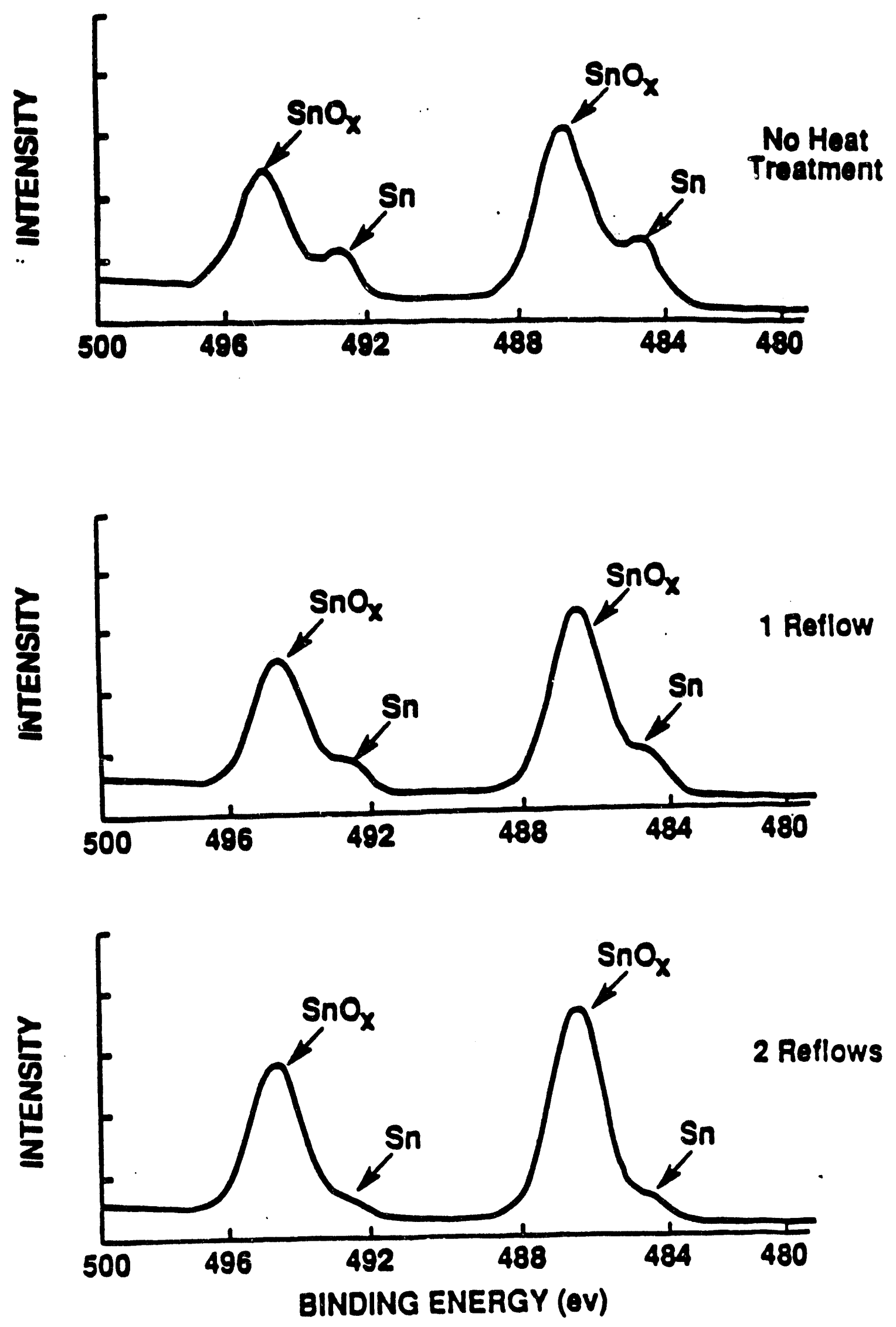

\section{XPS STUDIES OF IMMERSION TIN COATINGS Sn HIGH RESOLUTION SPECTRA}

FIGURE 2 

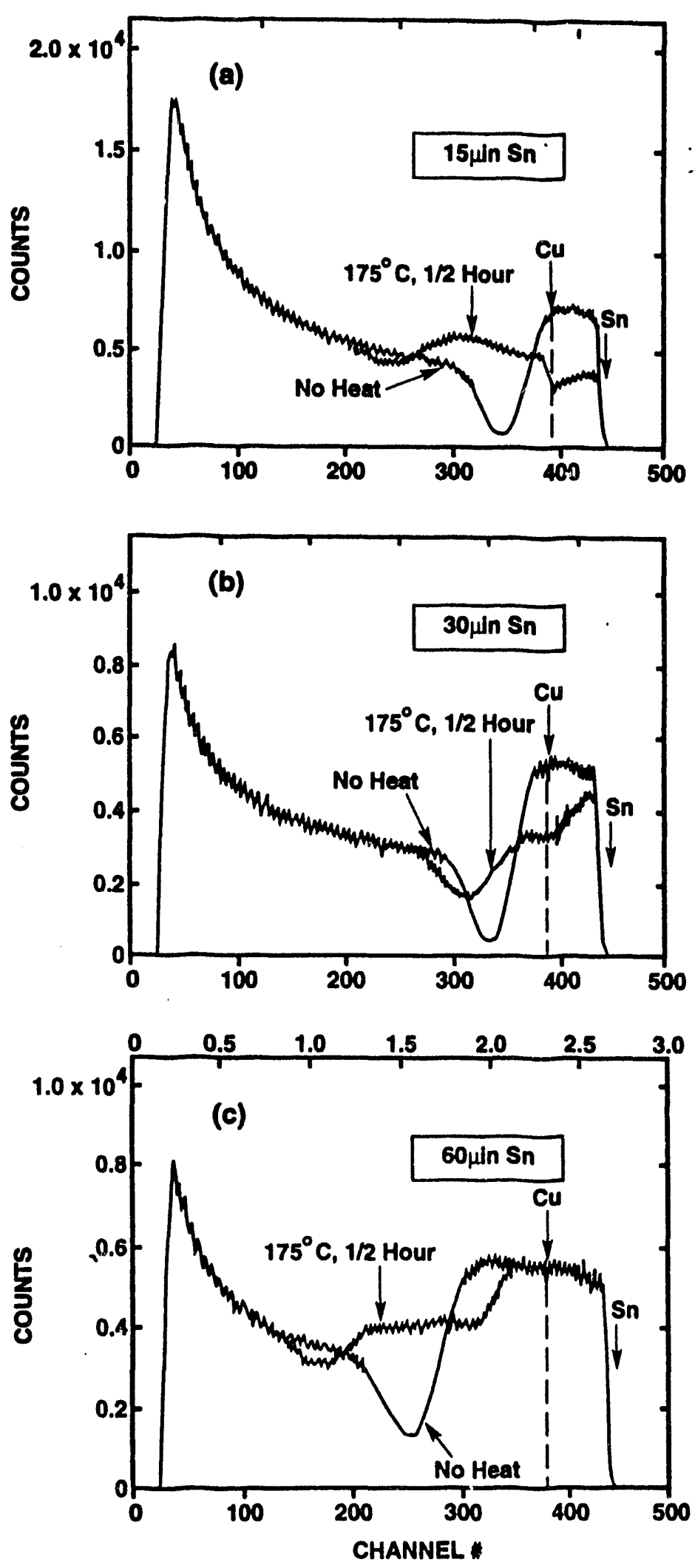

RBS SPECTRA OF IMMERSION TIN AS A FUNCTION OF FILM THICKNESS, BEFORE \& AFTER THERMAL TREATMENT

FIGURE 3 


\section{GLANCING INCIDENCE X-RAY DIFFRACTION SPECTRA OF IMMERSION TIN AFTER HEATING FOR 30 MINUTES AT $175^{\prime \prime} \mathrm{C}$}

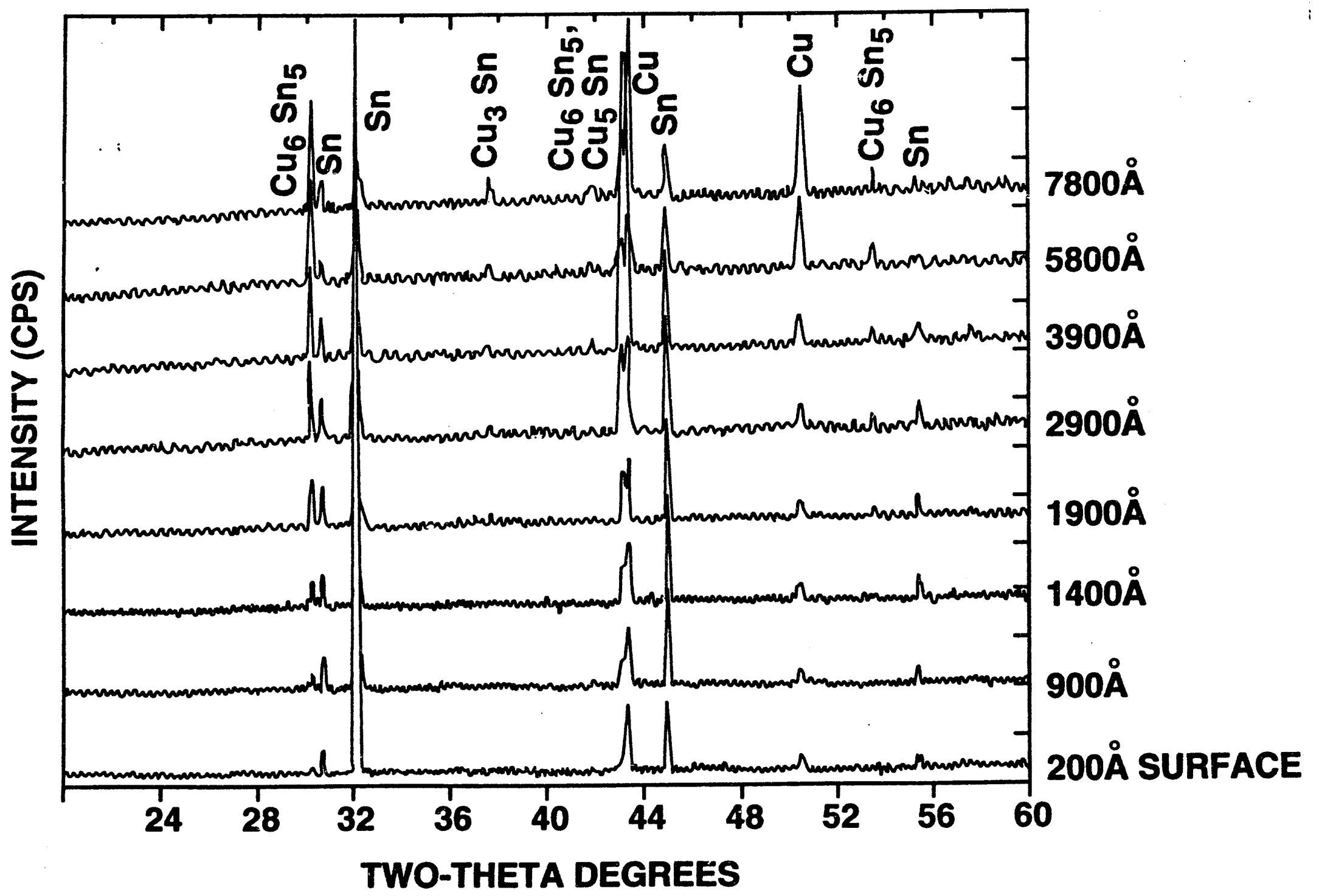

FIGURE 4 


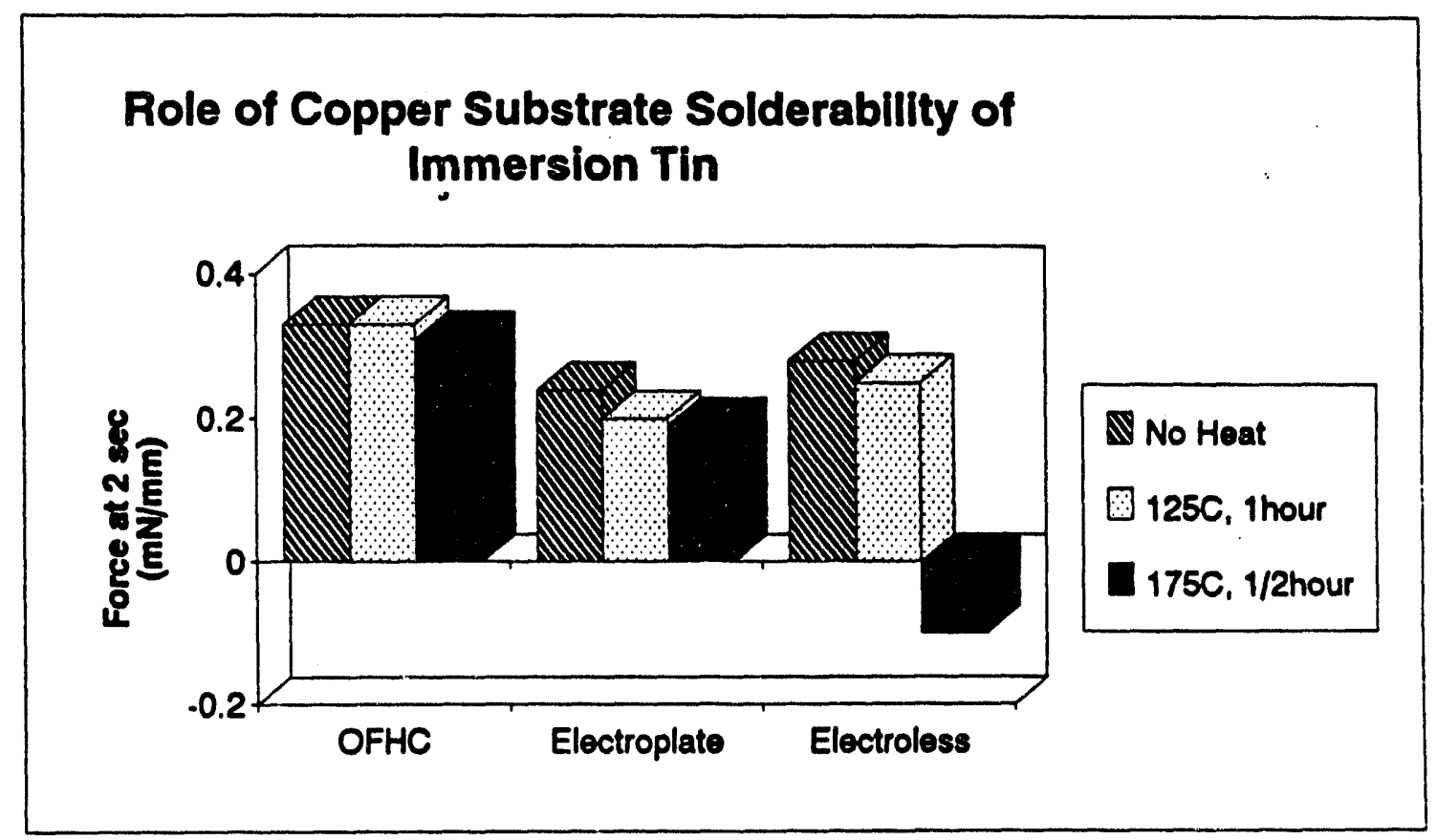

FIGURE 5 

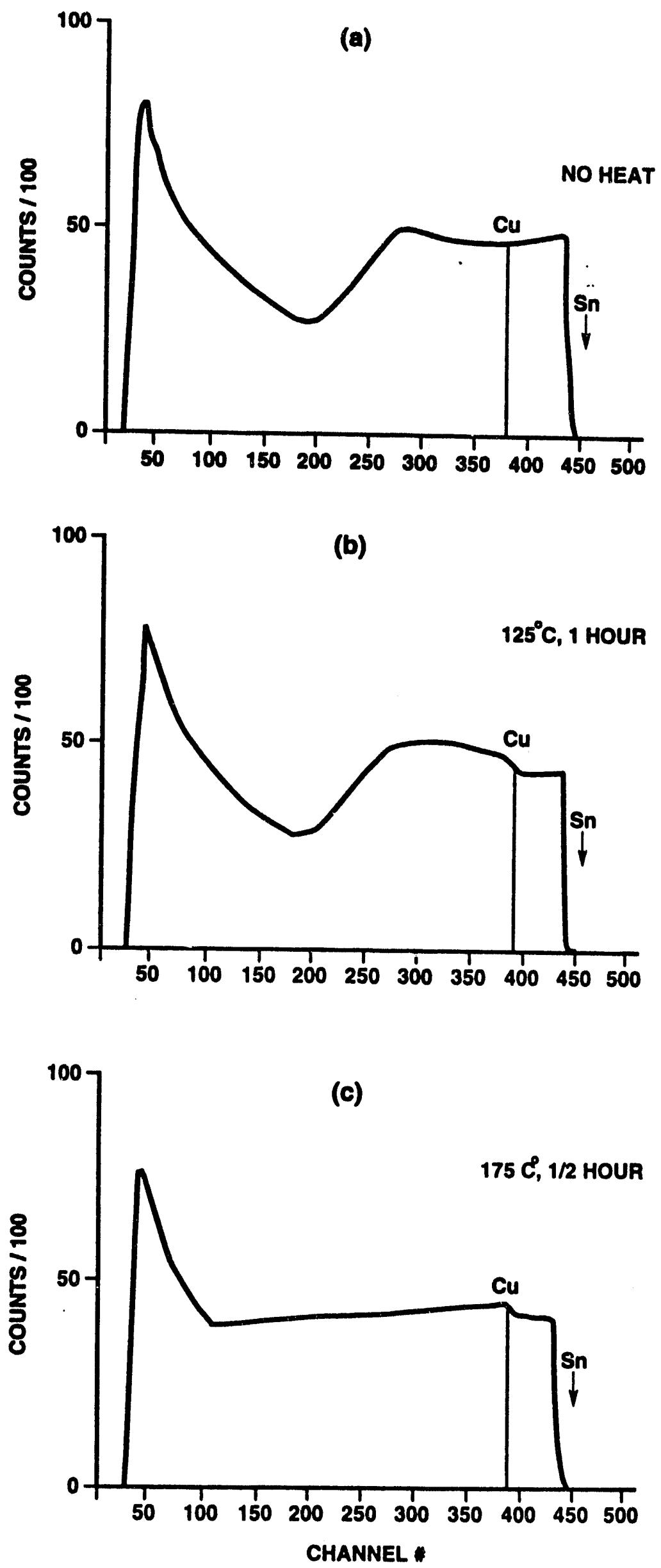

FIGURE 6 

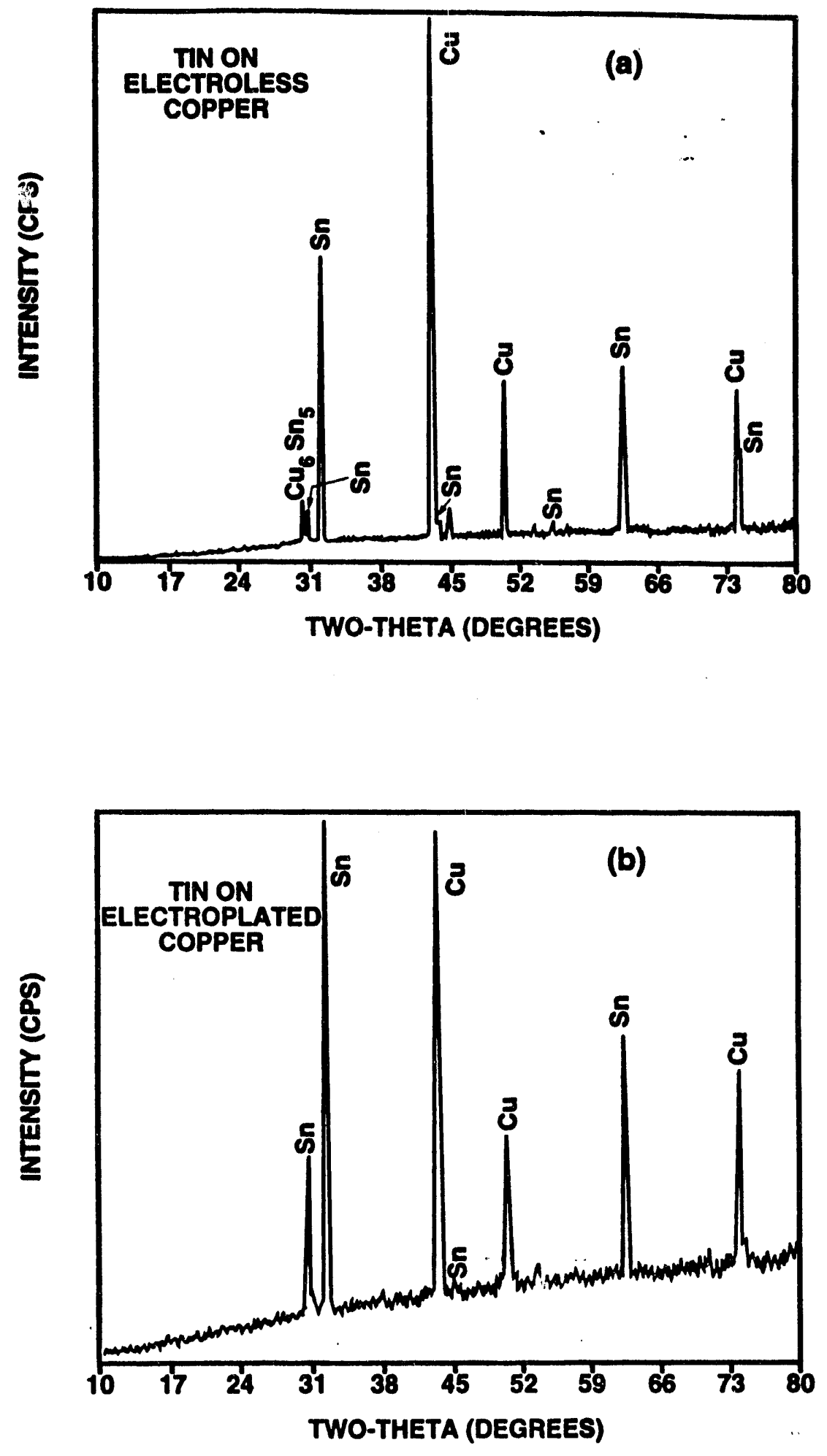

X-RAY DIFFRACTION SPECTRA OF

IMMERSION TIN ON ELECTROLESS AND ELECTROPLATED COPPER

FIGURE 7 
Solderability of Immersion Tin as a

Function of Temperature and Humidity

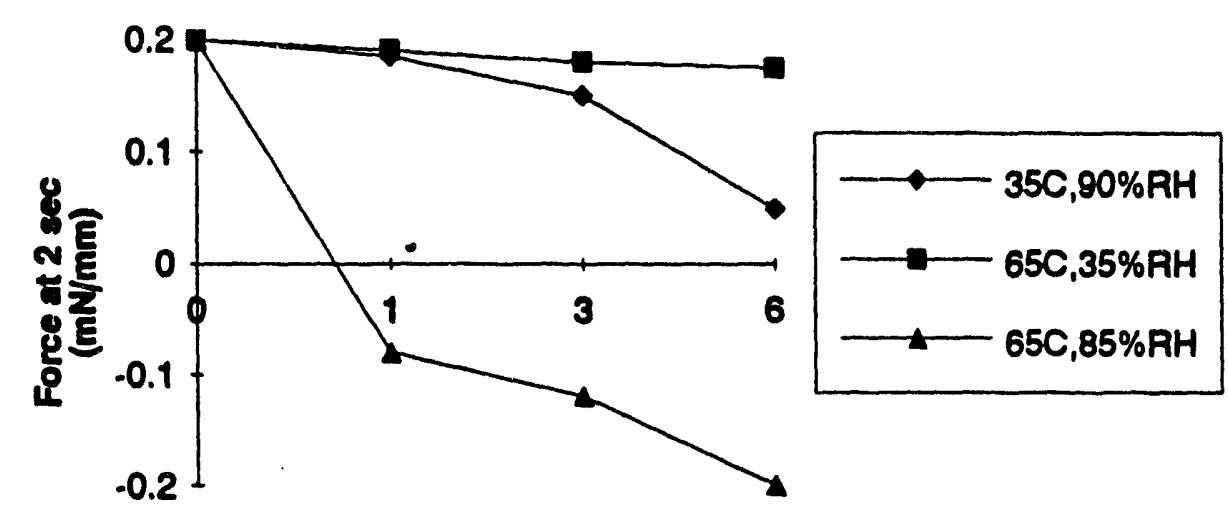

Exposure Time (Daye)

FIGURE 8 

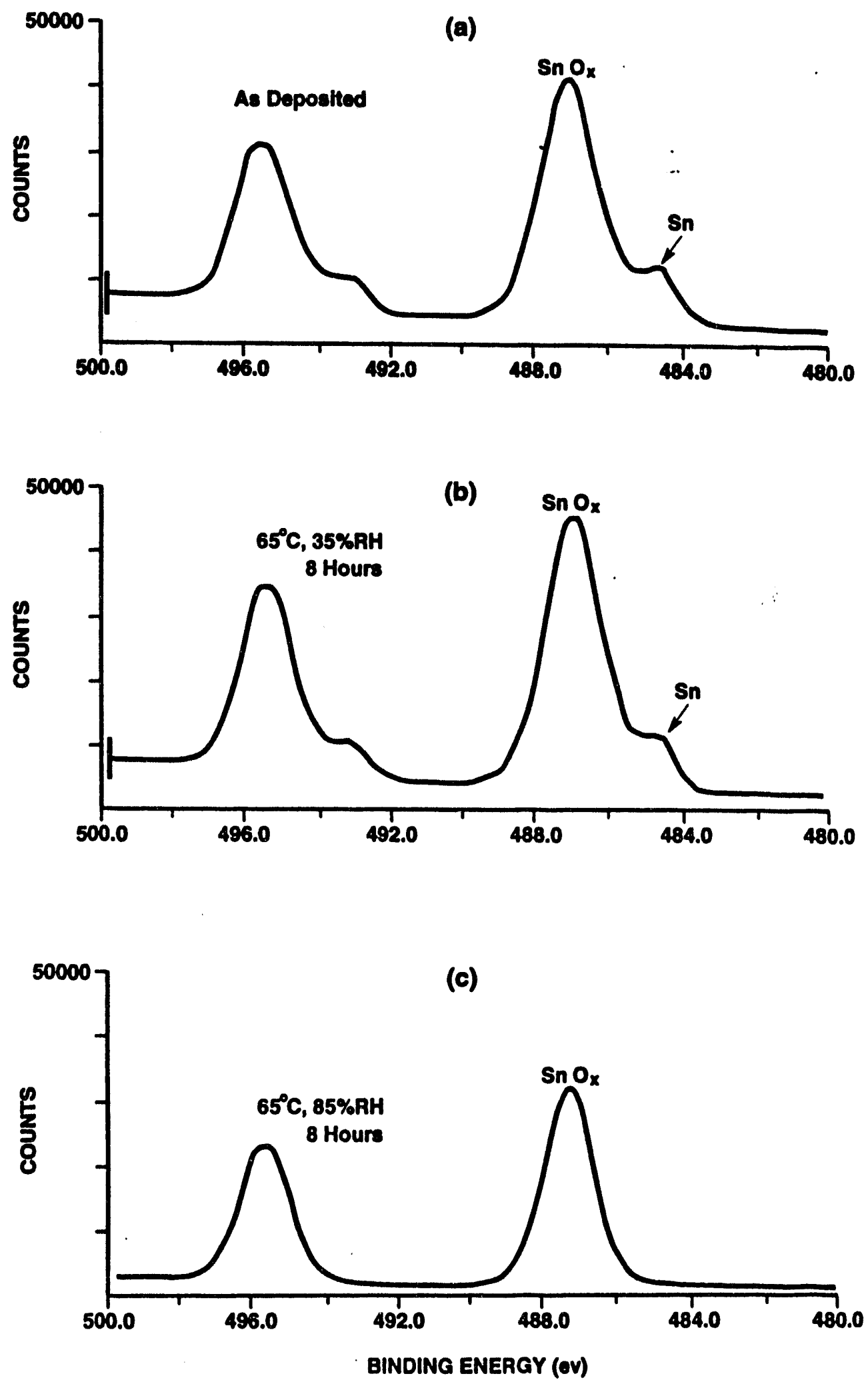

HIGH RESOLUTION XPS SPECTRA OF TIN COATINGS AFTER EXPOSURE TO TEMPERATURE AND HUMIDITY 


\section{Tin Oxide Growth by AES}

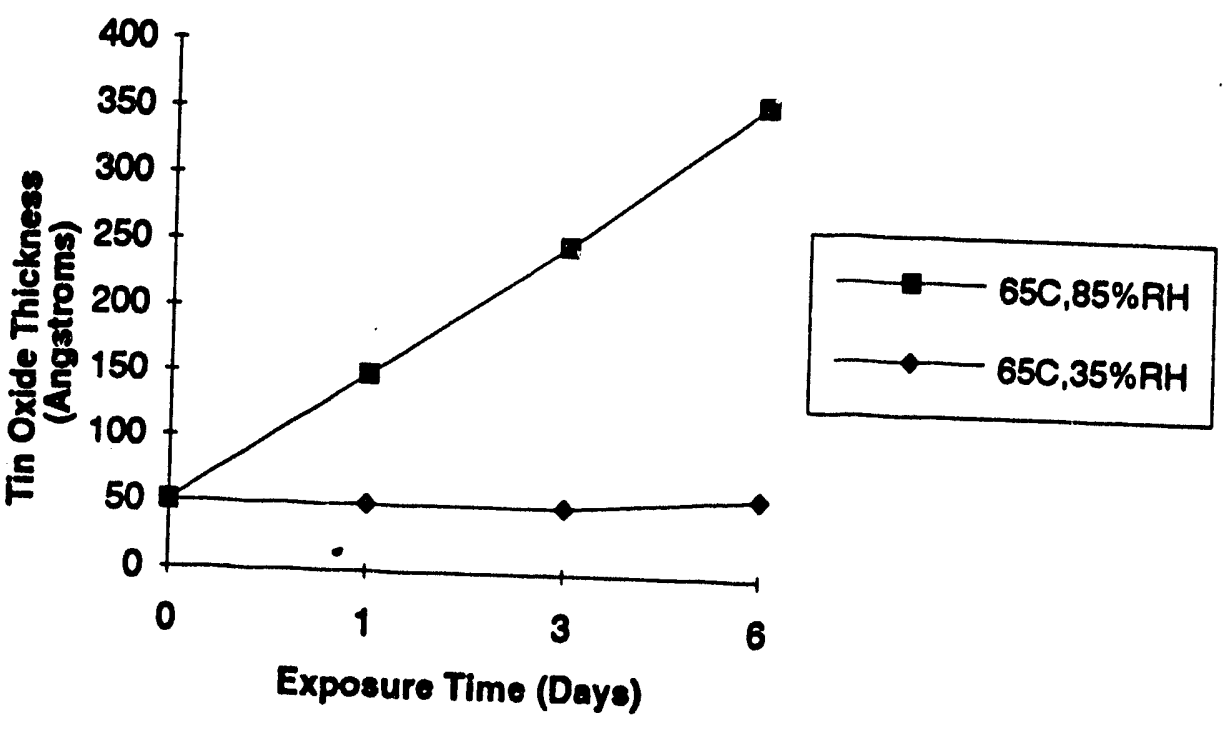

FIGURE 10 

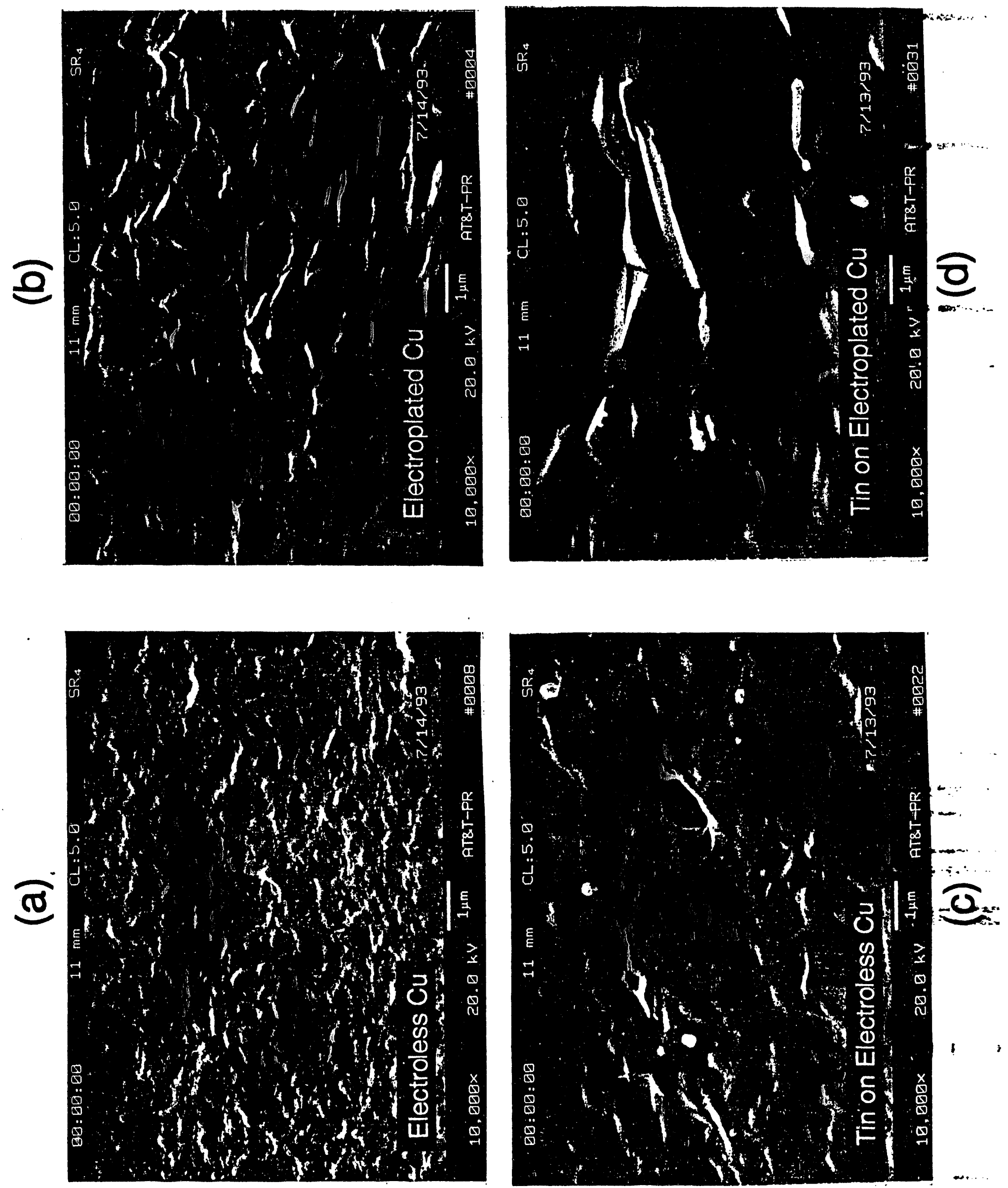


\section{Wetting Defects After SM Assembly with}

\section{Lead-Free Solder Pastes}

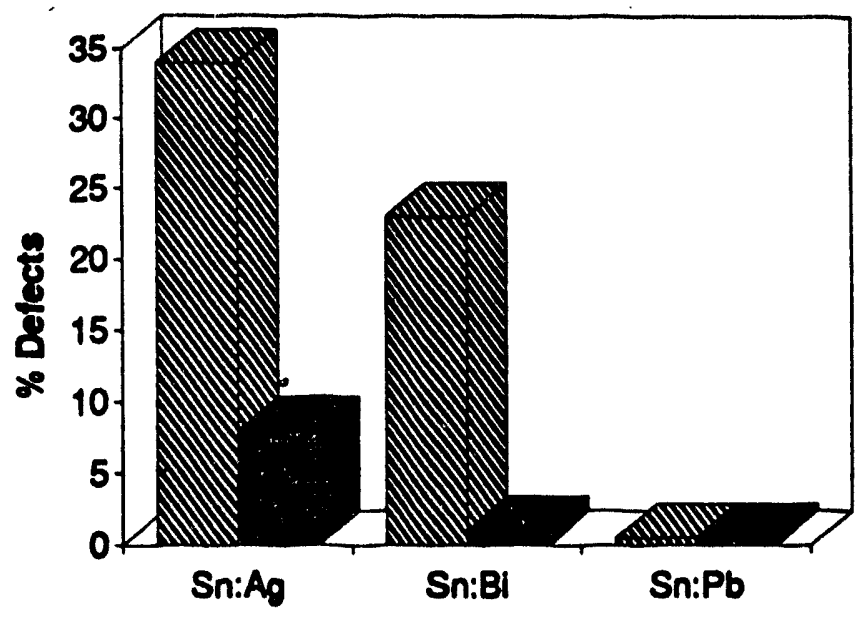

$\mathbb{N}$ Imidazole

Immersion Tin

FIGURE 12 


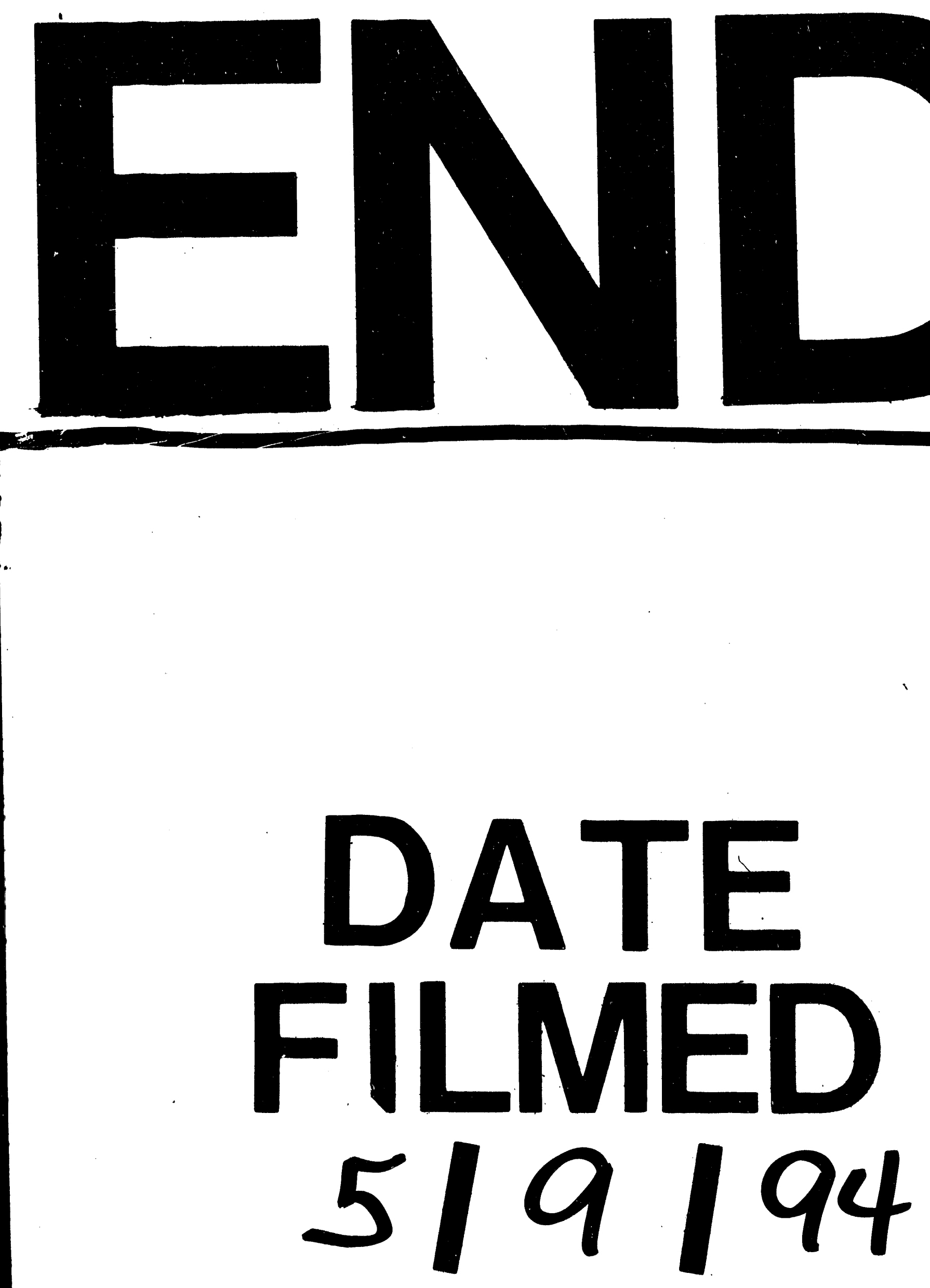


